\title{
A hemophilic patient presented with an abdominal mass, fever and cough
}

\author{
Mohammad Mizanur Rahman, Lutfunnahar Khan, Mohammad Shahidul Islam, Md. Monirul \\ Islam and Debashish Saha
}

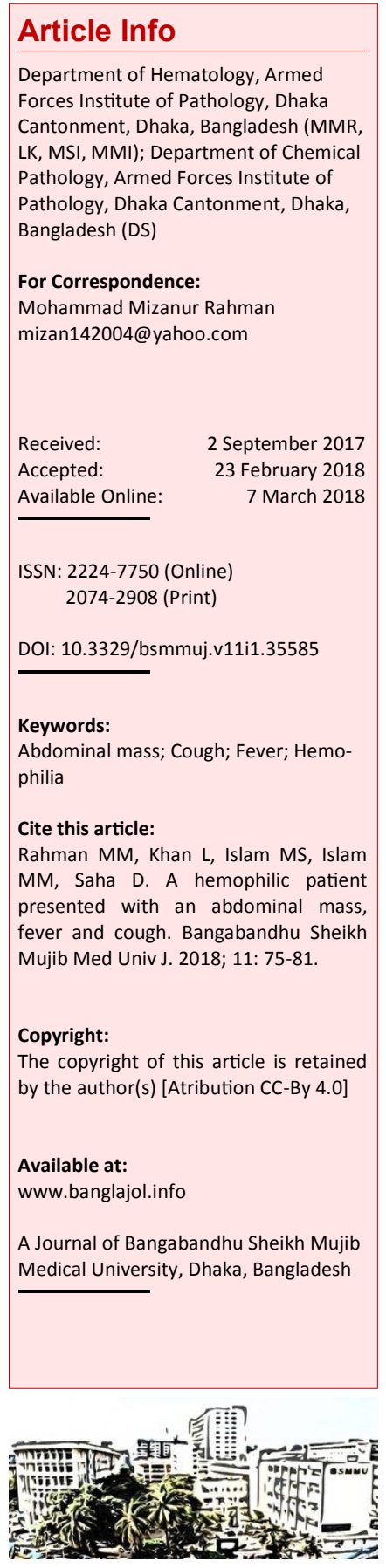

\section{Presentation of Case}

Mohammad Shahidul Islam (Hematology resident): A 30 year old male patient hailing from Jatrabari, Dhaka, the capital city of Bangladesh reported to the Department of Hematology, Armed forces Institute of Pathology, Dhaka Cantonment for the follow-up checkup of hemophilia A by assessing the factor VIII level. The patient had been suffering from mild rise of temperature, cough and weight loss for the last three months. So, he wanted to consult with a hematologist of the department. The concerned hematologist took detailed history of the patient and performed physical examination. History of the patient revealed cough, fever and mild weight loss for the last three months. The cough was productive and the sputum was moderate in amount, mucopurulent, not associated with hemoptysis and respiratory distress. Patient also complained of mild fever which was intermittent in nature and subsided after taking tablet paracetamol. He also told that he lost about 15-20 kg body weight during the last three months. He gave no history of diabetes mellitus, hypertension and informed that his bleeding episodes for hemophilia $\mathrm{A}$ is under control as he was taking injection recombinant FVIII regularly. His parents are alive and healthy. He is married and has two children, one son and one daughter, both are well. His two maternal uncles died of excessive bleeding following circumcision and road traffic accident respectively. There was no history of consanguineous marriage in his family. On examination, the patient was found mildly anemic, the temperature was $101^{\circ} \mathrm{F}$, abdomen was mildly distended and spleen was palpable about $12 \mathrm{~cm}$ from the left costal margin, soft in consistency, non-tender, movable, regular surface, notch was felt and it moved with respiretion. Liver was not palpable and there were no signs of ascities. On examination of the respiretory, cardiovascular, genitourinary, nervous and musculoskeletal system, no abnormality was detected. After analyzing the history and physical findings, I advised to perform complete blood count, peripheral blood film examination, sputum for acid fast bacilli, liver func- tion tests, blood for malarial parasites, renal function tests, hemoglobin electrophoresis, Xray chest (P/A view) and ultrasonography of the whole abdomen. I also advised to repeat activated partial thromboplastin time and factor VIII assay to see the status of hemophilia A. Therefore, on the basis of history and physical examination, a provisional diagnosis was made and advised to carry out some more investigations to confirm the diagnosis.

\section{Provisional Diagnosis}

Hemophilia A with pulmonary tuberculosis

\section{Differential Diagnosis}

Dr. Mohammad Mizanur Rahman: This patient was a diagnosed case of hemophilia $\mathrm{A}$ and recently developed some new complaints. So, I like to focus on the differential diagnoses related to cough, fever, mild anemia and moderate splenomegaly and try to explain the association between hemophilia A and other differential diagnosis, if any.

\section{Hemophilia A with pulmonary tuberculosis}

Tuberculosis is a contagious bacterial disease and the etiological agent is Mycobacterium tuberculosis. Any organ of the body may be affected by $M$. tuberculosis but lungs are the most common site. 1 In about $90 \%$ of cases, lungs are infected by $M$. tuberculosis when it is called pulmonary tuberculosis. 2 Patients with active pulmonary tuberculosis may be the source of M. tuberculosis which may be expelled during coughing, sneezing, speaking, singing and spitting containing infectious aerosol of 0.5 to $5.0 \mu \mathrm{m}$ in diameter. The infective dose of tuberculosis is more or less 10 bacteria and a single sneeze contains 40,000 droplets and each one of these droplets may transmit the disease. $\underline{3}$ People are more susceptible to tuberculosis when come to close, prolonged and frequent contact with patients with active tuberculosis. An estimated infection rate is $22 \%$ or may infect 


\section{$10-15$ people per year. $\underline{4,5}$}

There are many risk factors responsible for the development of tuberculosis. The most important factor at present in the world is human immunedeficiency virus. Other important risk factors are: Overcrowding, malnutrition, poverty, prisoners, homeless shelters, medically underprivileged people and resource-poor communities, high-risk ethnic minorities, children in close contact with high -risk category patients and health-care providers. Chronic lung disease and silicosis are also important risk factors. $\frac{6,7}{7}$ Pulmonary tuberculosis may be asymptomatic in about $20-25 \%$ of cases. Majority patients present with prolonged cough with the production of sputum. A small minority of patients may have hemoptysis and in some cases may cause massive bleeding if the infection nibbles the pulmonary artery. Fever, weight loss, night sweats and fatigue are the general signs and symptoms of tuberculosis. 8 An unusually high incidence of tuberculosis was found among patients with hemophilia in a study indicating a possible rudimentary defect in cell mediated immunity. .9

In this case, presence of fever, long-standing cough and weight loss with associated hemophilia favors the diagnosis of tuberculosis with hemophilia A but moderate splenomegaly is the point against the diagnosis of tuberculosis.

\section{Hereditary hemolytic anemia with hemophilia A}

Hereditary means that the parents usually passed the defective genes to their next generation. Hereditary hemolytic anemia is most commonly consociated with an anemia in early life. The anemia is refractory to conventional medical treatment. Also there may be family history of anemia, jaundice, unexplained splenomegaly and the development of cholelithiasis at an early age. $\underline{10}$ Chronic leg ulcers and bony abnormalities may occur less frequently.

There are various causes of hereditary hemolytic anemia. In these disorders, the genes that control red cell are defective. Different types of defective genes cause different types of hereditary hemolytic anemia. However, in each type of hereditary hemolytic anemia, abnormal red blood cells are produced in the body and these red cells are destroyed prematurely. The defective genes may affect the various components of the red cells such as hemoglobin, red cell enzymes and red cell membrane. In hereditary hemolytic anemia, the severity of anemia varies from one patient to another and severe disease is usually recognized immediately after birth or within the first year of life.

In most of the cases, anemia is mild to moderate in severity because the shortened red cell life span is partially compensated by bone marrow erythroid hyperplasia. Few patients may have no anemia at all and remain asymptomatic until late in adult life when jaundice, crisis or complications of gall bladder disease draw attention to the condition. Jaundice is another feature of the hereditary hemolytic anemia and may be first detected in the neonatal period. However, in older children and adults with hereditary hemolytic anemia, jaundice is absent or mild enough to pass unnoticed.11 In hereditary hemolytic anemia, spleen may be enlarged in some patients and it is usually mild to moderate in degree. But in severe hereditary hemolytic anemia such as beta thalassemia major or double heterozygous hereditary hemolytic anemia may have huge splenomegaly causing hypersplenism. $\underline{12}$

This patient presented with anemia and splenomegaly which is in favor of the diagnosis of hereditary hemolytic anemia but significant weight loss, absence of jaundice and negative family history of hereditary hemolytic anemia and no history of blood transfusion are the features which disfavor the diagnosis of hereditary hemolytic anemia.

\section{Chronic malaria with hemophilia A}

For many years, the term "asymptomatic" or "chronic malaria have been conceived and usually due to partial immunity (sometimes called premunition), which is capable of restricting the infection but not fully shutting out the infection. 13 Chronic or asymptomatic malaria is occasionally regarded as beneficial to the affected person, because it assists in preserving the premunition and decreasing the danger of fatal disease. 14 Definition of chronic malaria is hard to define but it is usually considered as malaria parasitemia of any density without fever or acute symptoms in persons who did not take antimalarial therapy in the recent past. $\underline{15}$ Such definition of chronic malaria rules out the early finding of uprising parasitemia that is not still a level of pyrogenic threshold as well as the symptoms of malaria are periodic and such symptoms are not that much serious to compel the individual to seek medical advice. $\underline{16}$

The signs and symptoms of malaria are directly related to the size of the infection biomass, the species and the duration of infection. Though pyrogenic threshold varies from individual to individual but it depends on the immunity of the individual, partial immune individuals require higher parasitemia than non-immune individuals. In Plasmodium vivax infection, the pyrogenic density is lower than the infection caused by Plasmodium falciparum. 17 Asymptomatic or chronic malaria usually cause chronic low-grade hemolysis as well as intermittent, high-density symptomatic recurrences. .18 Besides chronic continuous hemolysis, each attack of typical malaria leads to another session of hemolysis, with $10-15 \%$ loss of red blood cell mass. .19 Therefore, the more the attack of symptomatic malaria, the higher the hemolysis and the fall of hemoglobin. Also, if the condition continues for a longer duration, the more the damage of red cell 


\begin{tabular}{|c|c|c|}
\hline \multicolumn{3}{|c|}{ Table I } \\
\hline \multicolumn{3}{|c|}{ Laboratory Data } \\
\hline Variable & $\begin{array}{l}\text { Reference range, } \\
\text { Adult male }\end{array}$ & $\begin{array}{l}\text { In Hematology outpa- } \\
\text { tient department }\end{array}$ \\
\hline Hemoglobin (g/dL) & $13.0-17.0$ & 9.1 \\
\hline ESR (mm in $1^{\text {st }}$ hour) & $0-10$ & 22 \\
\hline Hematocrit (L/L) & $0.45-0.54$ & 0.27 \\
\hline $\mathrm{RBC}\left(\times 10^{12} / \mathrm{L}\right)$ & $4.5-5.5$ & 3.0 \\
\hline Mean cell volume (fL) & 83-101 & 89 \\
\hline White cell count (x109/L) & $4.0-10.0$ & 180.0 \\
\hline \multicolumn{3}{|l|}{ Differential count (\%) } \\
\hline Neutrophils & $40-80$ & 63 \\
\hline Lymphocytes & $20-40$ & 19 \\
\hline Monocytes & $2-10$ & 03 \\
\hline Eosinophils & $1-6$ & 03 \\
\hline Basophils & $0-1$ & 02 \\
\hline Blasts & 00 & 02 \\
\hline $\begin{array}{l}\text { Myelocytes + metamyelo- } \\
\text { cytes }\end{array}$ & 00 & 08 \\
\hline Platelet count $\left(\times 10^{9} / \mathrm{L}\right)$ & $150-410$ & 400 \\
\hline Peripheral blood film & & Suggestive of CML \\
\hline ICT for malaria & & Negative \\
\hline ICT for Kala-azar & & Negative \\
\hline Liver function tests & & Normal \\
\hline Random plasma sugar & & $4.8 \mathrm{mmol} / \mathrm{L}$ \\
\hline Urine $\mathrm{R} / \mathrm{M} / \mathrm{E}$ & & Normal \\
\hline Mantoux-test & & Negative \\
\hline Serum iron profile & & Normal \\
\hline Renal function tests & & Normal \\
\hline Hb electrophoresis & & Normal \\
\hline Bone marrow study & & Suggestive of CML \\
\hline
\end{tabular}

production and more hemolysis of non-parasitized red cells causing a severe anemia. $\underline{20}$ In chronic malaria, moderate to massive splenomegaly is a rule and mainly due to infiltration, accumulation and engulfment of parasitized red cells. Other factors which contribute splenomegaly in chronic malaria are the accumulation of red cell debris and dysfunctional uninfected erythrocytes. $\underline{21}$ Hyperreactive malarial splenomegaly is also a feature of chronic malaria due to antigenic stimulation secondary to malaria parasitemia. Hyper-reactive malarial splenomegaly usually leads to chronic hemolytic anemia, splenic rupture and make the affected individuals more prone to other acute infections. $\underline{\underline{22}}$

Anemia, fever and splenomegaly favor the diagnosis of chronic malaria with hemophilia A but weight loss, absence of chill and rigor with fever and residing in non-malaria zone are the points against the diagnosis of chronic malaria with hemo- philia A.

\section{Chronic myeloid leukemia with hemophilia A}

Chronic myeloid leukemia is a clonal bone marrow stem cell disorder and a form of myeloproliferative neoplasm characterized by uncontrolled proliferation of mature granulocytes and their precursors. The most striking feature of this leukemia is the presence of Philadelphia chromosome which is formed by a balanced reciprocal translocation between long arm of chromosome 9 and 22. Such translocation results in the formation of BCR-ABL1 fusion gene. There is no available data regarding the incidence of chronic myeloid leukemia in Bangladesh but in Western countries it accounts for about $15-25 \%$ of all adult leukemias. The onset of chronic myeloid leukemia is usually insidious and the disease is often discovered incidentally when a raised white cell count is detected during routine blood check up or an enlarged spleen is noticed during physical examination. $\underline{23}$ There are three phases, namely chronic phase, accelerated phase and blast phase through which chronic myeloid leukemia usually progresses. Chronic phase is characterized by excessive proliferation of mature white cells; in the accelerated phase, more complex cytogenetic abnormalities occur; in the blast phase, immature cells proliferate. About $85 \%$ of patients are diagnosed in the chronic phase and then advances to the accelerated and blast phase after 3-5 years. Middle-aged individuals are more commonly affected by chronic myeloid leukemia. However, the disease also occurs in younger individuals but the nature of the disease is fiercer, such as in accelerated phase or blast crisis. The diagnosis is usually made by the presenting signs and symptoms and examination of the peripheral blood film where complete spectrums of myeloid cells are found and by the detection of Philadelphia chromosome or BCR-ABL1 fusion gene. Bone marrow examination is not required as a routine method but may be done for cytogenetic and molecular testing which is essential for targeted therapy by tyrosine kinase inhibitor, imatinib mesylate. $\underline{24}$

As the patient presented with mild anemia, fever, weight loss as well as age of the patient and moderate splenomegaly strongly suggests the diagnosis of chronic myeloid leukemia with hemophilia A.

Dr. Islam: The patient after two days reported to the same department with all the laboratory and imaging reports which are shown in Table I. Complete blood count and peripheral blood film examination revealed the diagnosis of chronic myeloid leukemia. Figure 1 shows the peripheral blood film of my patient. Repetition of activated partial thromboplastin time and Factor VIII assay confirmed that the patient is also suffering from hemophilia A. As a part of management of the patient bone marrow aspiration was done and sent 


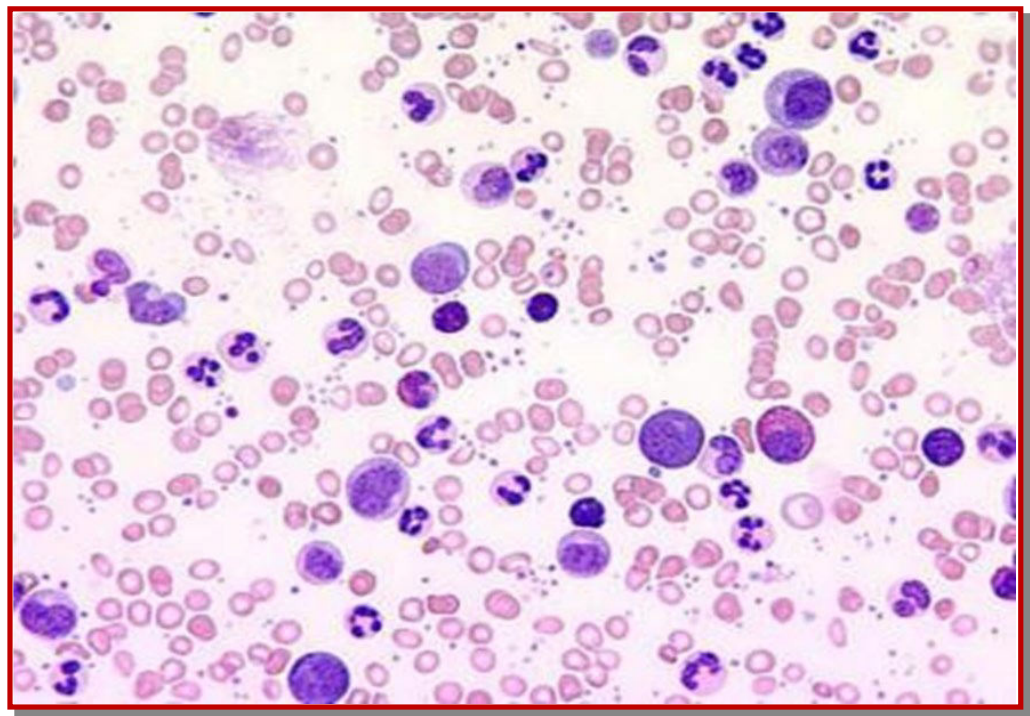

Figure 1: Peripheral blood film of the patient showing complete spectrum of white cell series

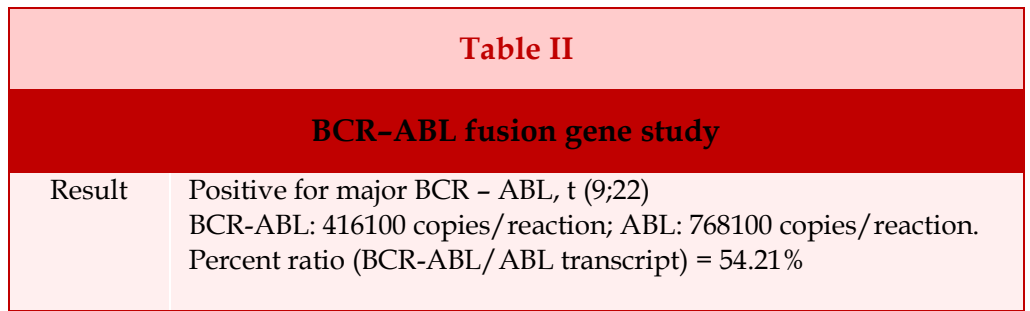

for morphological and molecular testing. Morphological examination revealed the findings consistent with chronic myeloid leukemia. Molecular analysis of bone marrow aspirate was done in Bangabandhu Sheikh Mujib Medical University and confirmed the presence of BCR-ABL1 fusion gene shown in Table II. Therefore, basing on the peripheral blood film, bone marrow findings and factor assay result, patient was diagnosed as chronic myeloid leukemia with hemophilia A.

\section{Dr. Islam's Diagnosis}

Chronic myeloid leukemia with hemophilia A

\section{Discussion}

Dr. Rahman: Hemophilia A is an X-lined recessive disorder due to deficiency of plasma coagulation factor VIII (FVIII), which may be inherited or arise from spontaneous mutation. New mutations or acquired immunologic process may also be responsible for the development of hemophilia A. $\underline{25}$

Among the X-linked genetic disease, hemophilia A is the most common and the second most common factor deficiency after von Willebrand disease (vWD). The worldwide incidence of hemophilia A is approximately 1 case per 5000 males, with approximately one third of affected individuals not having a family history of the disorder. $\underline{26}$

On the basis of severity, hemophilia A is classified into three categories such as severe hemophilia A when FVIII level is $<2 \%$ of normal, constitutes 50 $60 \%$ of patients and associated with severest bleeding manifestations. About $25-30 \%$ has moderate hemophilia A when FVIII level is in between 2-5\% of normal and manifest bleeding after minor trauma. Patients with mild hemophilia A have FVIII $6-30 \%$ of normal and comprise $15-20 \%$ of all people with hemophilia and associated with bleeding only after trauma or surgery.

Acquired FVIII deficiency (acquired hemophilia A) develops in 1case per 1 million populations per year and caused by the formation of an autoantibody to FVIII in a person with previously normal hemostasis. Acquired hemophilia A is usually found in older populations, generally those over 60 years. $\underline{27}$

Hemophilia A is a disease of male as it is an Xlinked recessive condition. Females usually are asymptomatic carriers. Females may have clinical bleeding due to hemophilia A if any of the three conditions is present: Extreme lyonization (i.e., inactivation of the normal FVIII allele in one of the $X$ chromosomes), homozygosity for the hemophilia A gene (i.e., father with hemophilia $\mathrm{A}$ and mother who is a carrier, two independent mutations, or some combination of inheritance and new mutations) and Turner syndrome (XO) associated with the affected hemophilia A gene. $\underline{28}$

The gene for FVIII (F8C) is located on the long arm of chromosome $\mathrm{X}$, within the $\mathrm{Xq} 28$ region. The gene is unusually large, representing $186 \mathrm{~kb}$ of the $\mathrm{X}$ chromosome. It comprises 26 exons and 25 introns. Approximately $40 \%$ of cases of severe FVIII deficiency arise from a large inversion that disrupts the FVIII gene. Deletions, insertions and point mutations account for the remaining $50-60 \%$ of the F8C defects that cause hemophilia A. 29

FVIII deficiency, dysfunctional FVIII, or FVIII inhibitors lead to the disruption of the normal intrinsic coagulation cascade, resulting in excessive hemorrhage in response to trauma and, in severe cases, spontaneous hemorrhage. Hemorrhage sites include joints (e.g., knee, elbow); muscles; the central nervous system; and the gastrointestinal, genitourinary, pulmonary, and cardiovascular systems. Intracranial hemorrhage occurs most commonly in patients younger than 18 years and can be fatal. With appropriate education and treatment, patients with hemophilia can live full and productive lives. Prophylaxis and early treatment with FVIII concentrate that is safe from viral contamination have dramatically improved the prognosis of patients with severe hemophilia. Nevertheless, approximately one quarter of patients with severe hemo- 
philia aged 6-18 years have below-normal motor skills and academic performance and have more emotional and behavioral problems than others. $\underline{30}$

Chronic myeloid leukemia is a hematological malignancy characterized by the accumulation of Philadelphia chromosome positive $(\mathrm{Ph}+)$ myeloid cells. Chronic myeloid leukemia has an estimated incidence of $1-1.5$ per 100,000 populations and represents approximately $15 \%$ of all leukemias diagnosed in adults with an onset at 40-50 years of age. $\underline{31}$ Chronic myeloid leukemia, a type of myeloproliferative disease, is characterized by the overproduction of both mature and immature myeloid cells causing high levels of white blood cell counts, splenomegaly, weight loss, fatigue and anemia. 32

Philadelphia chromosome positive $(\mathrm{Ph}+)$ myeloid cells are present in more than $90 \%$ of chronic myeloid leukemia patients. As a result of balanced reciprocal translocation between the Abelson gene (ABL1) on the long arm of chromosome 9 and the breakpoint cluster region gene $(\mathrm{BCR})$ on the long arm of chromosome 22, t $(9 ; 22)$ (q34; 111$)$, Philadelphia chromosome is formed. BCR-ABL1fusion gene is stirred as a result of such balanced translocation. 33 In different types of leukemia, various sizes of BCRABL fusion protein are synthesized. In more than $90 \%$ of chronic myeloid leukemia and $30-35 \%$ of acute lymphoblastic leukemia patients, a BCR-ABL protein of $210 \mathrm{kDa}$ is noticed. BCR-ABL proteins of 190 and $230 \mathrm{kDa}$ are tracked out in ALL and chronic neutrophilic leukemia respectively. $\underline{34}$ Malignant cell transformation results from tyrosine kinase activity of BCR-ABL oncoprotein. This oncoprotein phosphorylates target proteins through the activation of several signal transduction pathways leading to uncontrolled cell proliferation, decreased cell apoptosis, adhesion and differentiation of hematopoietic stem and progenitor cells. All these alterations form the phenotypic physiognomy of chronic myeloid leukemia. $\frac{35}{2}$ Chronic myeloid leukemia has an evolutional course comprising three clinical phases, known as chronic, accelerated and blast crisis phases, based on clinical and pathological features. The transition from chronic to accelerated phase and blast crisis phase results from secondary chromosomal aberrations such as trisomy 8, trisomy 19, an extra $\mathrm{Ph}$ chromosome and isochromosome $17 q(p 53$ gene on $17 p$ is lost)..$\underline{6}$

There is few case reports in which chronic myeloid leukemia developed in patients suffering from hemophilia A and B. $\frac{37,38}{4}$ A reciprocal influences between chronic myeloid leukemia and hemophilia may exist but exact pathogenesis needs to be explored. There are number of publication in which acquired hemophilia developed in patients suffering from acute myeloid leukemia or acute lymphoblastic leukemia or chronic lymphocytic leukemia. 39 , $\underline{40}$

The clinical features, physical findings, pedigree analysis of the patient as well as the result of coagulation testing (prothrombin time, APTT and FVIII assay) confirmed the diagnosis of hemophilia A at his childhood in this patient. With repeated whole blood, fresh frozen plasma and recombinant FVIII injection patient was passing well. But at the age of 29, the patient developed chronic myeloid leukemia which is confirmed by hematological and molecular investigations. Therefore, chronic myeloid leukemia developed in this hemophilic patient after two and half decades.

Dr. Md. Monirul Islam: Is there any relationship between hemophilia and chronic myeloid leukemia?

Dr. Shahidul Islam: Hemophilia is an inherited Xlinked recessive genetic disorder due to deficiency of plasma coagulation factor VIII whose gene is located on the long arm of chromosome X. Inversions, deletions, insertions and point mutations of FVIII gene (F8C) cause hemophilia A.29 On the other hand chronic myeloid leukemia is an acquired clonal stem cell disorder due to balanced reciprocal translocation between long arm of chromosome 22 and long arm of chromosome 9. $\underline{33}$ Therefore, there is no direct relationship between the two disorders but the improved life expectancy of hemophilic patients due to the advances in hemophilia care and factor replacement therapy has permitted to hemophiliacs to reach an older age. As a consequence, age-related diseases, such as cardiovascular disorders and cancer, have been increasingly recognized in such patients. $\underline{\underline{11}}$

Dr. Arif Ahmed Khan: Is there any data that treatment with rFVIII therapy increase the risk of CML?

Dr. Rahman: So far no such data is available. However, there are some studies to find out the relationship between hemophilia and cancer. The existence of a correlation between hemostasis and cancer was known nearly 150 years, as it was reported for the first time in 1865 by the French doctor, Armand Trousseau. 22 Since then, various investigators have analyzed this relationship, focusing on endogenous thrombin, which has been identified as a major contributor to tumor implantation, seeding and metastatisation. $\underline{4}$

Dr. Mehedi Hasan Shourav: Is there any difficulties in managing the CML of this patient?

Dr. Lutfunnahar Khan: In this patient, the two diseases will be managed simultaneously. Chronic myeloid leukemia will be managed by targeted therapy and hemophilia A by rFVIII injection.

Dr. Dildar Alam: Is the hemophilic patients are at increased risk of other malignancy?

Dr. Rahman: Human immunodeficiency virusassociated non-Hodgkin's lymphomas and hepatitis $\mathrm{C}$ virus (HCV)-associated hepatocellular carcinomas 
(HCC) are important causes of death among the virus-infected ageing hemophilia population. $\underline{44,45}$

Dr. Monwar Tarek: Is there data regarding the incidence of hematological malignancy in patients with hemophilia?

Dr. L. Khan: There is one study carried out on 1054 patients with hemophilia (PWH), nine patients $(0.85 \%)$ developed hematological malignancies, namely leukemia in six $(0.57 \%)$ and lymphoma in three (0.28\%) PWH.

Dr. Debashish Saha: Which type of leukemia more developed in hemophilic patients?

Dr. Rahman: No such data is available and also it is not clear that hemophilia increases the risk of developing leukemia. Huang's study $\underline{46}$ showed that among six PWH with leukemia, four had acute lymphoblastic leukemia and two had acute myeloid leukemia.

\section{Final Diagnosis}

Hemophilia A with chronic myeloid leukemia

\section{References}

1. Tuberculosis Fact Sheet N0 104. WHO October 2015.

2. Mandell GL, Bennett JE. In: Mandell, Douglas and Bennett's Principles and practice of infectious diseases. Mandell GL, Benett JE (eds). 7th ed. Philadelphia, Churchill Livingstone/Elsevier, 2010, p 250.

3. Nicas M, Nazaroff WW, Hubbard A. Towards understanding the risk of secondary airborne infection: Emission of respirable pathogens. J Occup Environ Hyg. 2005; 2: 143-54.

4. Ahmed N, Hasnain S. Molecular epidemiology of tuberculosis in India: Moving forward with a systems biology approach. Tuberculosis 2011; 91: 407-13.

5. Tuberculosis fact sheet $\mathrm{N}^{\circ} 104$. World Health Organization, 2010.

6. Griffith D, Kerr C. Tuberculosis: Disease of the past, disease of the present. J Perianesth Nurs. 1996; 11: 240-45.

7. ATS/CDC Statement Committee on Latent Tuberculosis Infection. Targeted tuberculin testing and treatment of latent tuberculosis infection. American Thoracic Society. MMWR. Recommendations and Reports, 2000; 49: 1-51.

8. Gibson PG, Abramson $\mathrm{M}$, Wood-Bracker R, Volmink J, Hensley M, Costabal U. In: Evidencebased respiratory medicine. Gibson PG, Abramson M, Wood-Bracker R, Volmink J, Hensley $M$,

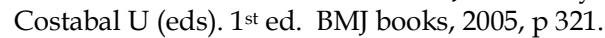

9. Beddall AC, Hill FGH, George RH, Williams MD, Al-Rubei K. An unusually high incidence of tuberculosis among boys with hemophilia during an outbreak of the disease in hospital. J Clin Pathol. 1985; 38: 1163-65.

10. Petz LD, Allen DW, Kaplan ME. Hemolytic anemia: Congenital and acquired. In: Manual of clinical hematology. Mazza JJ (ed). New York, Little Brown and Company, 1995, p 91.

11. Lee GR. Hemolytic disorders: General considerations. In: Wintrobe's Clinical hematology. Lee GR, Foerster J, Lukens J, Paraskevas F, Greer JP, Rodgers GM (eds). Philadelphia, Williams \& Wilkins, 1993, p 1109-13.

12. Saxena R, Pati HP, Mahapatra M. In: deGruchy's Clinical hematology in medical practice. Saxena $\mathrm{R}_{\text {, }}$ Pati HP, Mahapatra M (eds). New Delhi, Wiley, 2013, p 154.

13. Chen I, Clarke SE, Gosling R, Hamainza B, Killeen G, Magill A, O'Meara W, Price RN, Riley EM. Asymptomatic malaria: A chronic and debilitating infection that should be treated. PLoS Med. 2016; 13: e1001942.

14. Doolan DL, Dobano C, Baird JK. Acquired immunity to malaria. Clin Microbiol Rev. 2009; 22: 13-36.

15. Lindblade KA, Steinhardt L, Samuels A, Kachur SP, Slutsker L. The silent threat: Asymptomatic parasitemia and malaria transmission. Expert Rev Anti Infect. 2013; 11: 623-39.

16. Hamainza B, Moonga $\mathrm{H}$, Sikaala $\mathrm{CH}$, Kamuliwo $\mathrm{M}$, Bennett A, Eisele TP, Miller J, Seyoum A, Killeen GF. Monitoring, characterization and control of chronic, symptomatic malaria infections in rural Zambia through monthly household visits by paid community health workers. Malar J. 2014; 13: 128.

17. Mason DP, McKenzie FE. Blood-stage dynamics and clinical implications of mixed Plasmodium vivax -Plasmodium falciparum infections. Am J Trop Med Hyg. 1999; 61: 367-74.

18. Douglas NM, Lampah DA, Kenangalem E, Simpson JA, Poespoprodjo JR, Sugiarto P, Anstey NM, Price RN. Major burden of severe anemia from non-falciparum malaria species in southern Papua: A hospital-based surveillance study. PLoS Med. 2013; 2013.

19. Price RN, Simpson JA, Nosten F, Luxemburger C, Hkirjaroen L, ter Kuile FE, Chongsuphajaisiddhi T, White NJ. Factors contributing to anemia after uncomplicated falciparum malaria. Am J Trop Med Hyg. 2001; 65: 614-22.

20. Gwamaka M, Fried M, Domingo G, Duffy PE. Early and extensive CD55 loss from red blood cells supports a causal role in malarial anemia. Malar J. $2011 ; 2011$

21. Buffet PA, Safeukui I, Milon G, Mercereau-Puijalon $\mathrm{O}$, David PH. Retention of erythrocytes in the spleen: A double-edged process in human malaria. 
Curr Opin Hematol. 2009; 16: 157-64.

22. Leoni S, Buonfrate D, Angheben A, Gobbi F, Bisoffi Z. The hyper-reactive malarial splenomegaly: A systematic review of the literature. Malar J. 2015; 14: 185.

23. Sawyers CL. Chronic myeloid leukemia. N Engl J Med. 1999; 340: 1330-40.

24. Druker BJ, Sawyers CL, Kantarjian H. Activity of a specific inhibitor of the BCR-ABL tyrosine kinase in the blast crisis of chronic myeloid leukemia and acute lymphoblastic leukemia with the Philadelphia chromosome. N Engl J Med. 2001; 344: 1038-42.

25. Peyvandi F, Garagiola I, Young G. The past and future of haemophilia: Diagnosis, treatments, and its complications. Lancet 2016; 3: 15056.

26. Hemophilia: Data \& Statistics. Centers for Disease Control and Prevention. Available at http:// www.cdc.gov/ncbddd/hemophilia/data.html. July 11, 2016.

27. Shetty S, Bhave M, Ghosh K. Acquired hemophilia A: Diagnosis, etiology, clinical spectrum and treatment options. Autoimmun Rev. 2011; 10: 311 16.

28. Di Michele DM, Gibb C, Lefkowitz JM, Ni Q, Gerber LM, Ganguly A. Severe and moderate hemophilia A and B in US females. Hemophilia 2014; 20: e136-43.

29. Pinto P, Ghosh K, Shetty S. F8 gene mutation profile in Indian hemophilia A patients: Identification of 23 novel mutations and factor VIII inhibitor risk association. Mutat Res. 2016; 786: 27-33.

30. Loveland KA, Stehbens J, Contant C, Bordeaux JD, Sirois P, Bell TS. Hemophilia growth and development study: Baseline neurodevelopmental findings. J Pediatr Psychol. 1994; 19: 223-39.

31. Jabbour E, Kantarjian HM. Chronic myeloid leukemia: Update on diagnosis, monitoring and management. Am J Hematol. 2012; 87: 1037-45.

32. Federal S, Kantarjian HM, Talpaz M. Chronic myeloid leukemia: Update on biology and treatment. Oncology 2012; 13: 169-80.

33. Al-Achkar W, Wafa A, Moassass F, Othman MAK. A novel dic $(17 ; 18)$ (p13.1;q11.2) with loss of TP53 and $\mathrm{BCR} / \mathrm{ABL}$ rearrangement in an imatinib resistant chronic myeloid leukemia. Mol Cytogenet. 2012; 5: 36 .

34. Chan LC, Karhi KK, Rayter SI, Heisterkamp N, Eridani S, Powle R, Lawler SD, Groffen J, Foulkes JG, Greaves MF, Wiedemann LM. A novel abl protein expressed in Philadelphia chromosome positive acute lymphoblastic leukemia. Nature 1987; 325: 635-37.

35. Jagani Z, Singh A, Khosravi-Far R. FoxO tumour suppressors and BCR-ABL induced leukemia: A matter of evasion of apoptosis. Biochim Biophys Acta. 2008; 63: 85.

36. Al-Achkar W, Wafa A, Mossass F, Othman MAK. A novel dic $(17 ; 18)$ (p13.1;q11.2) with loss of p53 and BCR-ABL rearrangement in an Imatinib resistance chronic myeloid leukemia. Mol Cytogenet. 2015; 5: 36.

37. Larrain C. Chronic Myeloid Leukemia in hemophilia B. Rev Med Chill. 2002; 130: 897-900.

38. Ghosh K, Mohanty D, Deshpande AS, Das KC. Chronic myeloid leukemia in a hemophiliac. Blut 1987; 54: 369-70.

39. Fozza C, Bellizi S, Piseddu G, Porcu A, Dore F, Longinotti $M$. Acquired hemophilia in a patient affected by acute myeloid leukemia. AJH. 2005; 79: 81-82.

40. Mahipal A, Bilgrami S. Acquired hemophilia in chronic lympho-cytic leukemia. Leuk Lymphoma. 2007; 48: 1026-28.

41. Franchini M, Lippi G, Montagnana M, Targher G, Zaffanello M, Salvagno GL, Rivolta GF, Di Perna C, Tagliaferri A. Hemophilia and cancer: A new challenge for hemophilia centre. Cancer Treat Rev. 2009; 35: 374-77.

42. Trousseau A. Phlegmasia alba dolens. In: Trousseau A, editor. Clinique medicinale de l'Hotel -Dieu de Paris. Paris, France: JB Bailliere et fils, 1865, 645-712.

43. Hu L, Lee M, Campbell W. Role of endogenous thrombin in tumor implantation, seeding, and spontaneous metastasis. Blood 2004; 104: 2746-51.

44. Darby SC, Ewart DW, Giangrande PL. Mortality from liver cancer and liver disease in hemophilic men and boys in UK given blood products contaminated with hepatitis C. UK Hemophilia Centre Directors' Organization. Lancet 1997; 350: 1425-31.

45. Ragni MV, Belle SH, Bass D. Clinical characteristics and blood product usage in AIDS-associated lymphoma in hemophiliacs: A case-control study. Hemophilia 1998; 4: 826-35.

46. Huang YC, Tsan YT, Chan WC, Wang JD, Chu WM, Fu YC, Tong KM, Lin CH, Chang ST, Hwang WL. Incidence and survival of cancers among 1,054 hemophilia patients: A nationwide and 14-year cohort study. AJH. 2015; 90: E55-59. 